\title{
Variations of Crest-to-Trough TEC Ratio of the East African Equatorial Anomaly Region
}

\author{
Bosco Oryema ${ }^{1, *}$, Edward Jurua ${ }^{2}$, Nicolausi Ssebiyonga ${ }^{3}$ \\ ${ }^{1}$ Department of Physics, Busitema University, Tororo, Uganda \\ ${ }^{2}$ Department of Physics, Mbarara University of Science and Technology, Mbarara, Uganda \\ ${ }^{3}$ Department of Physics, Makerere University, Kampala, Uganda
}

Email address:

oryemabosco@gmail.com (B. Oryema), ejurua@gmail.com (E. Jurua),nssebiyonga@physics.mak.ac.ug (N. Ssebiyonga)

\section{To cite this article:}

Bosco Oryema, Edward Jurua, Nicolausi Ssebiyonga. Variations of Crest-to-Trough TEC Ratio of the East African Equatorial Anomaly Region. International Journal of Astrophysics and Space Science. Vol. 4, No. 1, 2016, pp. 12-20. doi: 10.11648/j.ijass.20160401.12

\begin{abstract}
In this paper, Vertical Total Electron Content (VTEC) data derived from dual-frequency GPS measurements obtained at two ground stations were used to study the variability of the equatorial ionization anomaly (EIA). The present study only focuses on analysis of the crest-to-trough TEC ratio (TEC-CTR) in the southern crest region. Data used in this study was obtained for the high solar activity year 2012. MAL2 station (Geomag Lat. $-12.4^{\circ} \mathrm{S}$, Geomag Long. $111.9^{\circ} \mathrm{E}$ ) was considered for the southern crest region whereas ADIS station (Geomag Lat. $0.2^{\circ} \mathrm{N}$, Geomag Long. $110.5^{\circ} \mathrm{E}$ ) was considered for the trough region. Diurnal and seasonal variations as well as the dependency of TEC-CTR on solar activity levels were investigated in the present study. The results showed that the diurnal variation pattern of TEC-CTR is characterized by two remarkable peak values, one occurring in the post-midnight hours around 02: 00-03: 00 UT (05: 00-06: 00 LT) and the second (highest) peak occurred in the post-sunset hours around 18: 00-20: 00 UT (21: 00-23: 00 LT). Seasonal TEC-CTR variations showed a semi-annual variation pattern, with maximum peak values occurring in the equinoctial months. TEC-CTR also revealed an existence of winter anomaly in this region, with higher values of TEC-CTR in the winter solstice than summer solstice. TEC-CTR in the daytime post-noon hours; between 01: 00-04: 00 UT (04: 00-07: 00 LT) does not vary much with the solar activity; however, TEC-CTR in the post-sunset hours; between 16: 00-20: 00 UT (19: 00-23: 00 LT) shows a clear dependence on the solar activity, with its values increasing with solar activity.
\end{abstract}

Keywords: Total Electron Content (TEC), Equatorial Ionization Anomaly (EIA), GPS Measurements, Solar Activity

\section{Introduction}

The atmosphere in which we live is composed of several layers, one of which is the ionosphere. This layer contains charged particles that are generated as a result of the interactions between the short wavelength solar radiations ( $\mathrm{x}$-rays and EUV) and neutral particles in the upper atmosphere (Memarzadeh, 2009). The Earth's ionosphere along equatorial and low-latitude region is quite unique and different from that at the mid and high latitude regions (Chakraborty and Hajra, 2009). This is because the equatorial ionosphere is characterized by a trough region around the magnetic equator, bordered by two crest regions on both sides (Schunk and Nagy, 2000). The trough region at the magnetic equator and the crest regions near $\pm 15^{0}$ geomagnetic latitude are caused by the formation of an equatorial plasma fountain (Tsai et al., 2001). During the daytime, the eastward equatorial electric field lifts the ionospheric plasma upwards into higher altitudes, while the reverse occurs at night. Once the plasma is transported to higher altitudes, it diffuses downward along the geomagnetic field lines into both hemispheres due to gravitational and pressure gradient forces (Kelley 1989; Fejer et al., 1999). This combination of electromagnetic drift and diffusion produces a fountain like pattern of plasma motion called the equatorial fountain. This leaves region around the magnetic equator with little electron density concentration, and higher electron density concentrations at the crests or equatorial anomaly regions (Schunk and Nagy, 2000). This implies that ionospheric effects such as time delay, scintillations and TEC variations are higher around the equatorial crests than at the trough region or magnetic equator. However, the latitudes of the anomaly crests and strength of the anomaly vary with condition of the day, season of the year and solar activity 
(Chakraborty and Hajra, 2009; Yeh et al., 2001; Wu et al., 2008; Tsai et al., 2001).

Along the African equatorial ionosphere, variations in total electron content (TEC) are the most extensively investigated parameter of the equatorial ionization anomaly (EIA) (e. g. Fayose et al., 2012; Adewale et al., 2011; Ouattara et al., 2011; Okonkwo and Ugwuanyi, 2012; Zoundi et al., 2012; D'ujanga et al., 2012; Oron et al., 2013; Paznukhov et al., 2012; Olwendo et al., 2012; Ngwira et al., 2013a; Ngwira et al., 2013b; Oryema et al., 2015 etc). These previous studies revealed some remarkable behaviors of EIA along the African region. It showed that ionospheric TEC values do not only have diurnal variations but also depend on seasons of the year, latitudes and solar activity levels. Furthermore, they are known to have north/south asymmetry and remarkable longitudinal differences (Paznukhov et al., 2012; Ngwira et al., 2013b). The highest day-to-day TEC values were observed around 18: 00 UT and highest seasonal values exhibited during equinoctial months, moderate in the summer solstice and least in the winter solstice.

Much as variations of the latitudinal positions and amplitudes of EIA along the African equatorial region have been extensively studied using GPS derived TEC data, the crest-to-trough ratio (CTR) parameter of EIA seems not to have been adequately studied for this region. The crest-totrough TEC ratio (TEC-CTR) can be considered as a measure of the strength of the fountain effect which produces EIA. The degree of the development of an EIA is of key importance in the generation and development of the Equatorial Spread F (ESF) irregularities that have significant impacts on telecommunication systems (Zhang et al., 2009). A well-developed EIA is one of the conditions conducive for the generation of ESF and scintillation effects which disrupt trans-ionospheric radio wave propagation (Alex et al., 1989; Jayachandran et al., 1997; Valladares et al., 2001, 2004; Henderson et al., 2005). This occurs when an Equatorial Plasma Bubble (EPB) intersects the maximum electron density of the equatorial anomaly (Whalen, 2004). Since TEC-CTR variations are closely related to the generation and development of the ESF irregularities, EPB and ionospheric scintillations, this suggests that TEC-CTR of EIA is an important parameter that can be used to study the dynamics of the equatorial ionosphere.

\section{Data and Measurements}

The GPS data used in this study were obtained from two selected operational IGS receiver stations located within the region of interest and downloaded from Scripps Orbit and Permanent Array Centre (SOPAC) website (http: //www.sopac.ucsd.edu), and processed using the Gopi GPSTEC analysis application software, version 2.2 (Seemala and Valladares, 2011). These stations are Addis Ababa, Ethiopia (Geomag Lat. $0.2^{\circ} \mathrm{N}$, Geomag Long. $110.5^{\circ} \mathrm{E}$ ) and Malindi, Kenya (Geomag Lat. $-12.4^{\circ} \mathrm{S}$, Geomag Long. $\left.111.9^{\circ} \mathrm{E}\right)$. Only two stations were considered for this study because they have complete data for the year 2012. The codes ADIS and MAL2 were used to respectively represent the stations as seen in Fig. 1. In the present study, MAL2 station was considered for the equatorial crest region since it's located close to the geomagnetic southern crest region. While ADIS station was considered for the trough region since it's located at the magnetic equator. This study only focused at investigating crest-to-trough ratios of TEC for the southern crest region.

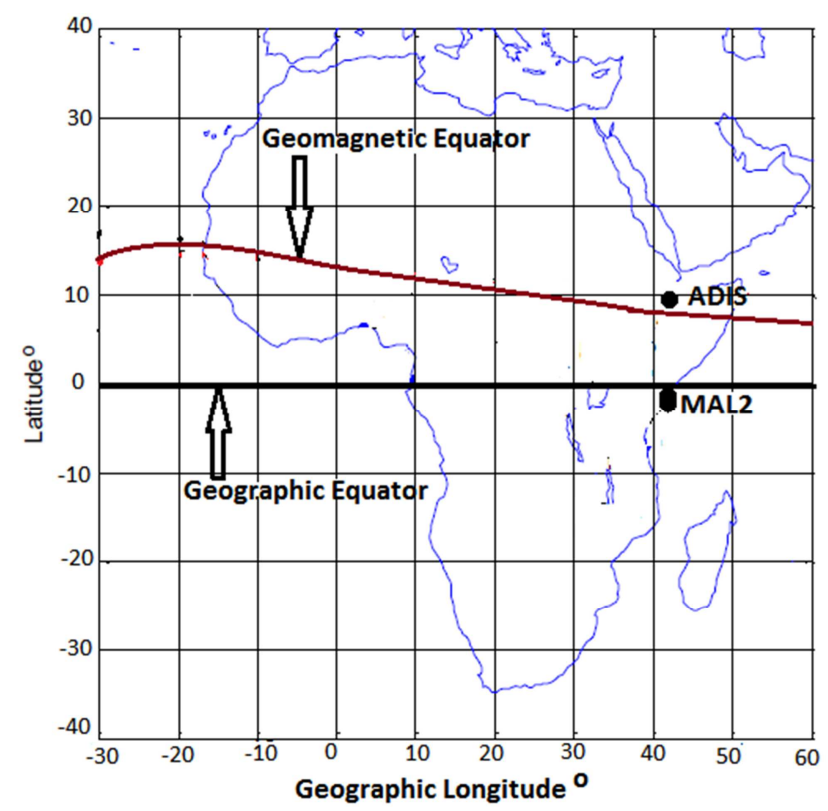

Fig. 1. Map of Africa showing locations of the IPS receiver stations used in this study.

The GPS signals recorded at these two ground-based IGS receiver stations were then used to derive slant TEC (STEC) by the general approach of combining the GPS pseudorange and phase measurements with satellite and receiver biases (Klobuchar, 1991; Lanyi and Roth, 1988; Sardon, et al., 1994). STEC is the number of electrons in a volume of one square meter cross-section along the GPS ray path from a satellite to a receiver (Zhao et al., 2009). Due to dispersive nature of the earth's ionosphere, the pseudorange and phase signals may be delayed by significant amounts. Therefore, STEC can be obtained from the difference between the pseudo-ranges $\left(P_{1}\right.$ and $\left.P_{2}\right)$, and the difference between the phases $\left(L_{1}\right.$ and $\left.L_{2}\right)$ of the two signals (Klobuchar, 1996). The relevant equations are (Zhao et al., 2009);

$$
\begin{aligned}
& \operatorname{STEC}_{L}=\left[\left(\frac{f_{2}^{2}}{f_{1}^{2}-f_{2}^{2}}\right) \frac{2 f_{1}^{2}}{K}\right]\left(P_{2}-P_{1}\right) \\
& \operatorname{STEC}_{P}=\left[\left(\frac{f_{2}^{2}}{f_{1}^{2}-f_{2}^{2}}\right) \frac{2 f_{1}^{2}}{K}\right]\left(L_{1} \lambda_{1}-L_{2} \lambda_{2}\right)
\end{aligned}
$$

where $f_{1}$ and $f_{2}$ are GPS signal frequencies and are equal to $1.57542 \mathrm{GHz}$ and $1.2276 \mathrm{GHz}$, respectively, $\mathrm{K}=80.62$ 
$\mathrm{m} 3 \mathrm{~s}-2$ is a constant that relates plasma frequency to electron density, $\lambda_{1}$ and $\lambda_{2}$ are the wavelengths corresponding to $f_{1}$ and $f_{2}$ respectively.

The STEC extracted from the differential pseudorange GPS signals $\left(S T E C_{L}\right)$ are strongly affected by multipath effects, especially at low elevation angles. Multipath is caused by reflection and diffraction of the satellite signals by nearby objects (Abdullah et al., 2008). Because of the extra path length travelled, multipath signals usually arrive at the antenna with a delay relative to the direct signal, introducing strong fluctuations that may exceed the expected TEC values. Thus, the TEC estimations based on pseudorange difference can have large errors and so be rather uncertain (Hansen et al., 2000). Since STEC from differential phase $\left(S T E C_{P}\right)$ are less affected by multi-path effects (Klobuchar, 1996; Jakowski et al., 1996), it provides smoother and high precision measurements of STEC. However, because of the $2 \pi$ ambiguity in phase measurements (Zhao et al., 2009), the absolute value of STEC cannot be determined. Hence, it's preferable to resort to the STEC from differential pseudoranges $\left(S T E C_{L}\right)$ because it can provide absolute values of TEC aside the multipath effect. Therefore, to retain the relative accuracy of the phase path measurements, the $\left(S T E C_{P}\right)$ values for a given satellite pass are fitted to the level of the $\left(S T E C_{L}\right)$ measurements to give STEC expressed as (Zhao et al., 2009);

$$
\begin{aligned}
& \text { STEC }=\text { STEC }_{P}+B_{\text {corr }} \\
& B_{\text {corr }}=\sqrt{\sum_{i=1}^{N}\left(\frac{\left(S T E C_{L}-S T E C_{P}\right)^{2}}{N}\right)}
\end{aligned}
$$

$N$ are measurements obtained during a satellite pass.

In order to convert STEC into vertical TEC (VTEC) which is a more useful parameter for describing the overall ionization of the ionosphere, the STEC (corrected for both satellite and receiver biases) is divided by a mapping function, $M(\varepsilon)$ as (Horvath and Essex, 2000);

$$
V T E C=\frac{S T E C_{\text {corrected }}}{M(\varepsilon)}=\left(S T E C-B_{S}-B_{R}\right)\left\{1-\left(\frac{R_{E} \times \cos (\varepsilon)}{R_{E}+h_{m}}\right)^{2}\right\}^{0.5}
$$

$$
M(\varepsilon)=\frac{1}{\cos (z)}=\left\{1-\left(\frac{R_{E} \times \cos (\varepsilon)}{R_{E}+h_{m}}\right)^{2}\right\}^{-0.5}
$$

where

$B_{S}$ and $B_{R}$ are the instruction biases of satellites and receivers respectively, $M(\varepsilon)=$ mapping function, $\mathrm{Z}=$ zenith angle of the satellite, $R_{E}=$ Earth's radius, $\varepsilon=$ elevation angle in radians, $h_{m}=$ altitude of the thin layer above the surface of the Earth (taken as $400 \mathrm{~km}$ for this paper).

In determining the mapping function, the Earth's ionosphere is assumed to be equivalent to a thin-shell model encircling the Earth at a fixed height $\left(h_{\mathrm{m}}\right)$ in the range 350-400 km (Klobuchar, 1996; Horvath and Essex, 2000). Thus it is assumed that there are no horizontal gradients along the slant line of sight path from the satellite to the ground station (Schaer et al., 1996). The choice of $h_{\mathrm{m}}$ is not particularly critical though significant. Titheridge (1972) made extensive calculations with theoretical electron density profiles and showed that a global average height of $420 \mathrm{~km}$ is appropriate for oblique to vertical conversion. Using different thin-shell heights for different local times and seasons of the year, Breed (1996) demonstrated the magnitude of the error arising from an incorrect choice of median height are insignificant for measurements at an elevation angle greater than $15^{\circ}$. He found that $400 \mathrm{~km}$ is an appropriate height for the oblique to vertical conversion. For this paper, $h_{\mathrm{m}}=400 \mathrm{~km}$ has been used to convert STEC to VTEC.
In order to eliminate errors in TEC due to multipath effects, data recorded for which satellite elevation angles were less than $30^{\circ}$ were not considered in this study. The solar F10.7 flux data used in this study was obtained from the Earth Orientation Parameters and Space Weather (website: http: //celestrak.com/space-data/). In order to obtain TECCTR, TEC at crest station (MAL2) was divided by its corresponding value at the trough station (ADIS) as discussed in detail in Section 3.

\section{Results and Discussion}

\subsection{Diurnal TEC-CTR Variations}

Fig. 2 shows TEC-CTR variations as a function of universal time (UT) and the days of the year, 2012. TECCTR values used for this plot were obtained by getting the ratio of daily maximum TEC values at the crest (MAL2) station to the daily maximum TEC values at the trough (ADIS) station.

From Fig. 2, it can be seen that there are unique diurnal behaviors of TEC-CTR. These are seen through the two peak values of TEC-CTR, one occurring in the early morning hours around 02: 00-03: 00 UT (05: 00-06: 00 LT), and the other occurring late in the evening hours around 18: 00-20: 00 UT (21: 00-23: 00 LT). This can be seen much more clearly in Fig. 3 which shows the statistical month-by-month plots of diurnal TEC-CTR variations. 


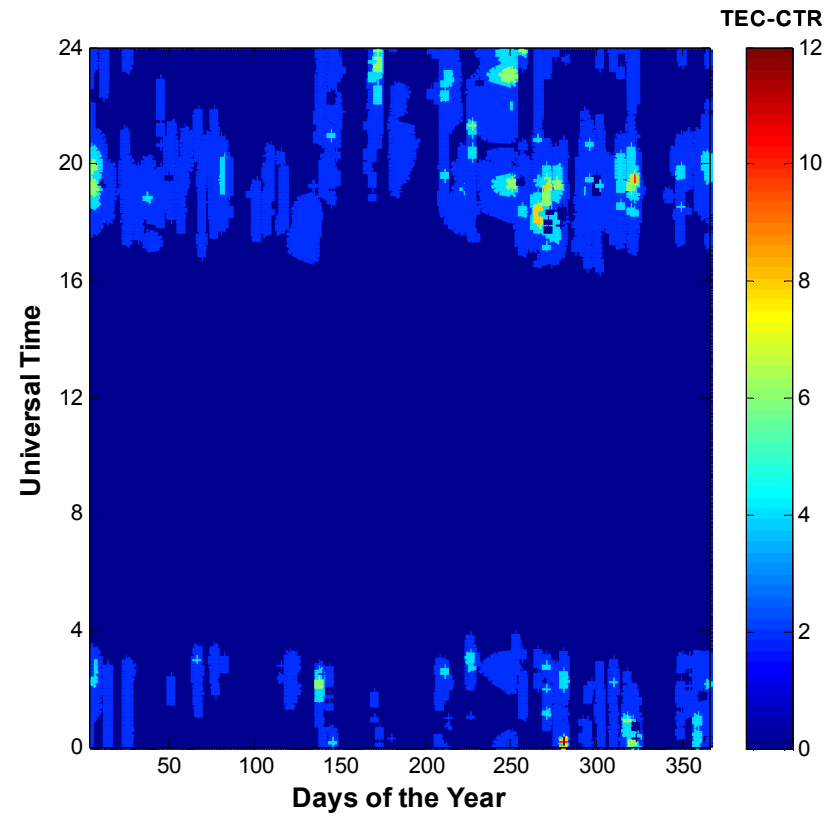

Fig. 2. Contour plot showing variation of the crest-to-trough TEC ratios of Equatorial Ionization Anomaly for the year 2012.
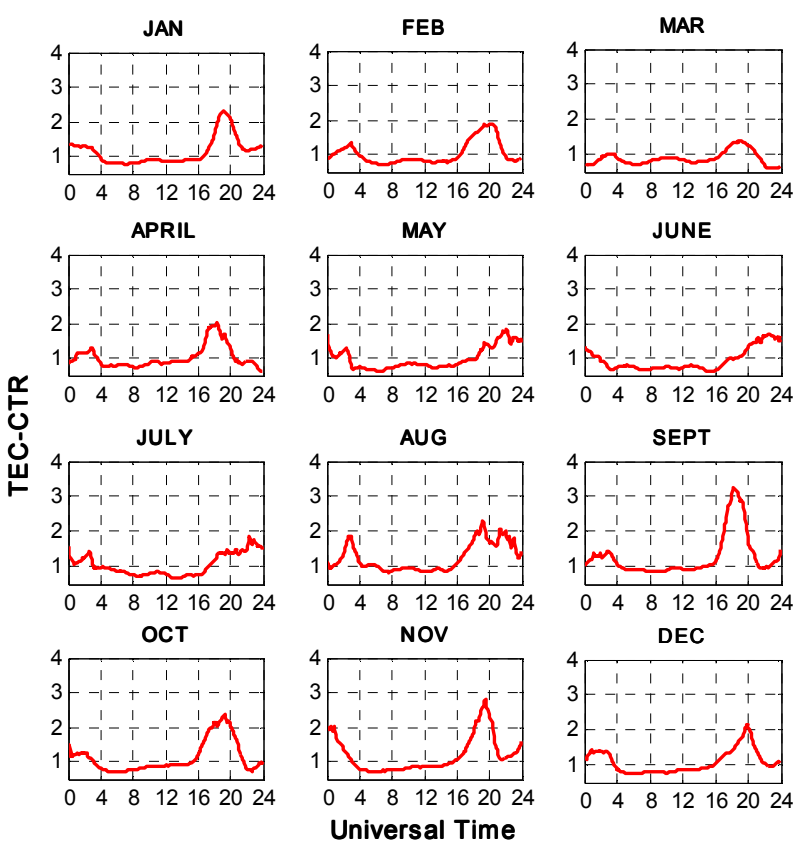

Fig. 3. Diurnal variation of the TEC-CTR of Equatorial Ionization Anomaly for the 12 months of the year 2012.

In order to obtain TEC-CTR values used in Fig. 3, vertical TEC data with half-hour time resolution for each day of available dataset at both stations were used. From Fig. 3, it can be clearly seen that the most remarkable features for the diurnal variation of TEC-CTR are the two peak values, one occurring in the post-midnight hours around 02: 00-03: 00 UT (05: 00-06: 00 LT) and the other occurring in the postsunset hours around 18: 00-20: 00 UT (21: 00-23: 00 LT). It was observed that for all the months, post-sunset peaks had higher TEC-CTR values than the post-midnight peaks. This nighttime enhancement in TEC-CTR in the post sunset hours could have resulted from enhancement/regeneration of the fountain effect responsible for the formation of the crest and trough regions of EIA along the equatorial region (Mukherjee et al., 2010). The regeneration/enhancement of the fountain effect occurs as a result of the evening pre-reversal build-up of the $\mathrm{F} 2$ region plasma's electromagnetic $\overrightarrow{\mathrm{E}} \times \overrightarrow{\mathrm{B}}$ drift driven by the enhanced zonal electric field near the magnetic equator (Fejer et al., 1995). This leads to formation of huge clouds of electrons at the crest region ionosphere.

It can also be seen from Fig. 3 that TEC-CTR values for the September equinox is much larger than that of the March equinox. This indicates an existence of equinoctial asymmetry. The existence of equinoctial symmetry has been reported earlier by Titheridge (1973), Essex (1977), Titheridge and Buonsanto (1983) and Feichter and Leitinger (1997). However, the mechanism of this equinoctial asymmetry was not fully understood until Balan et al. (1998) carried out, for the first time, analysis using all the parameters measured by the MU radar at Shigaraki $\left(35^{\circ} \mathrm{N}\right.$, $136^{\circ} \mathrm{E}$ ) during the solar maximum period $1988-1992$ to study the altitude dependence of plasma density asymmetry. Their results reveal that the meridional component of the daytime poleward wind velocity at $300 \mathrm{~km}$ was weaker in the March equinox than in September equinox by up to $20 \mathrm{~m} / \mathrm{s}$, and the values of the daytime [O/N2] ratio obtained from MSIS-86 were larger in the September equinox than in the March equinox by $20 \%$. Balan et al. (1998) showed that the equinoctial asymmetries in the ionosphere arose mainly from the corresponding asymmetries in the thermosphere, with major contributions from neutral winds and minor contributions from composition.

In the years that followed, a number of studies (e. g. Bailey et al., 2000; Richards, 2001; Chakraborty and Hajra, 2007; Zhao et al., 2007; Liu et al., 2010; Kherani et al., 2013; Yue et al., 2015; Oryema et al., 2015 etc) have reported the existence of equinoctial asymmetry in ionospheric parameters such as TEC, NmF2, hmF2 and TEC-CTR. Most of them attributed this phenomenon to have been caused by dynamic factors such as neutral atmospheric temperature, composition of $\mathrm{O} / \mathrm{N}_{2}$ ratio and vertical electric field drift. High neutral temperature may cause an increased circulation from the Southern Hemisphere to the Northern Hemisphere during the March equinox, which would then deplete the atomic oxygen density, and lower the electron density in the ionosphere (Richards, 2001; Zhao et al., 2007). While the flow of meridional wind increases the neutral composition and $\mathrm{O} / \mathrm{N}_{2}$ ratio during the September equinox, which results in higher electron density (Kherani et al., 2013; Zhao et al., 2007). These two factors could be the main causes of the equinoctial asymmetry observed in this study.

Fig. 4 shows the diurnal variations of TEC over ADIS and MAL2 stations. TEC values used in plotting this figure were obtained at a sampling rate of five (5) minutes. This interval was chosen for convenience since it is small enough to observe changes in TEC values within a day. A single 24-h running mean dataset were obtained and plotted against universal time as shown in Fig. 4. A close analysis of Fig. 4 
reveals that TEC at EIA's crest (MAL2) station during the post-sunset hours around 18: 00-20: 00 UT (21: 00-23: 00 LT) was slightly enhanced than TEC at EIA trough (ADIS) station which was much more reduced during this time. Since TEC-CTR values in this case are ratios of TEC at MAL2 station to TEC at ADIS station, the large discrepancies seen between crest region and trough region TEC values could have led to the large enhancement of TEC-CTR during the post-sunset hours. This seems to suggest that the post-sunset enhancement of TEC-CTR is due to the regeneration/enhancement of the fountain effect after sunset. Regeneration of the EIA strength or the fountain strength after sunset is particularly strong for the equinoctial months during the high solar activity years (Farley et al., 1986; Chakraborty and Hajra, 2007).
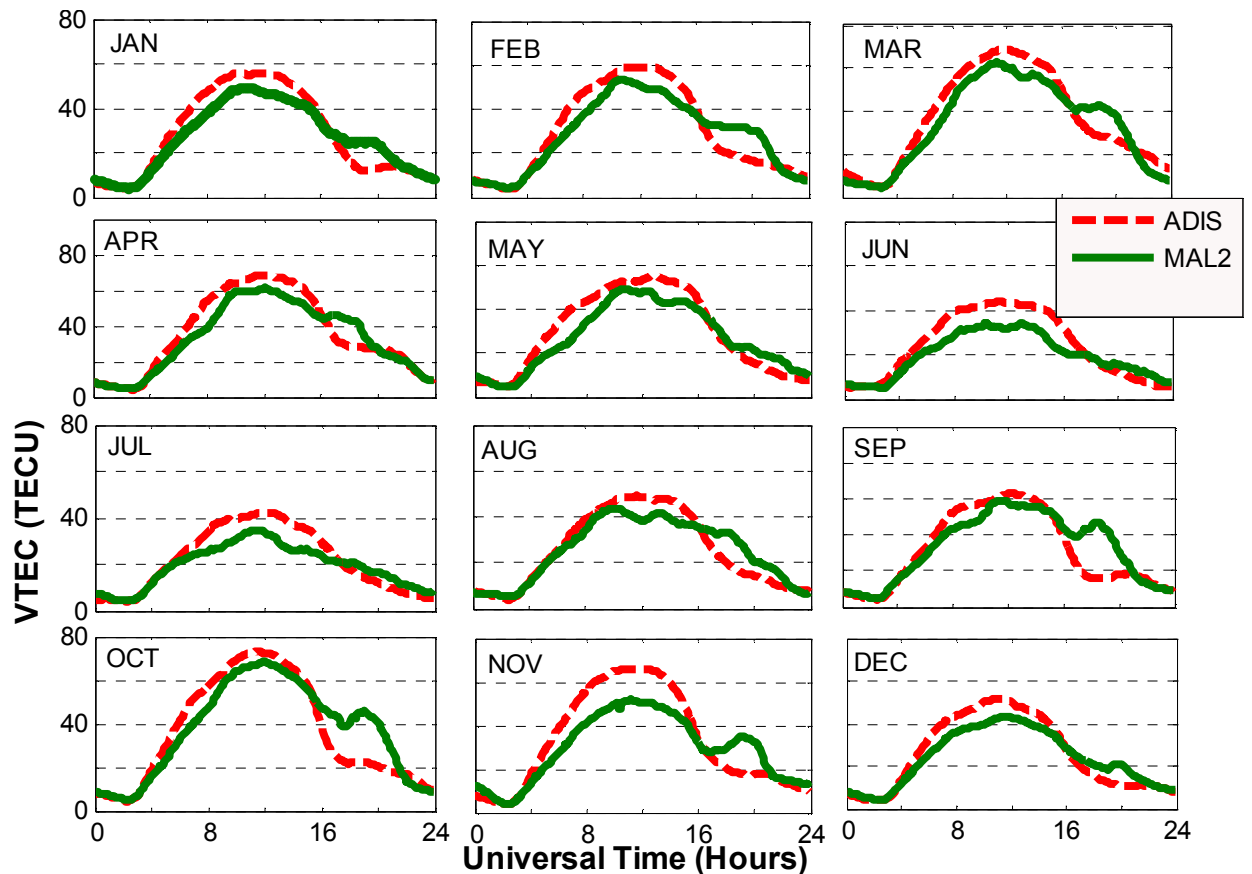

Fig. 4. Diurnal variations in TEC. The dotted red line shows diurnal TEC variations at ADIS station whereas the full green line shows diurnal TEC variations at MAL2 station.

\subsection{Dependency of TEC-CTR on Solar Activity Levels}

In order to further investigate whether the difference in TEC-CTR values between the pre-sunrise and post-sunset peaks had any dependency on solar activity, mean TEC-CTR values for the two time bins i. e. post-midnight hours (01: 0004: 00 UT or 04: 00-07: 00 LT) and post-sunset hours (16: 00-20: 00 UT or 19: 00-23: 00 LT) were used. These values were separately plotted against the mean F10.7 solar fluxes as shown in Figs. 5 and 6 respectively. The two time bins used correspond to the time within which TEC-CTR values are enhanced. It can be seen from Figs. 5 and 6 that the dependence of TEC-CTR values on solar activity is different for the two time bins. For the 01: 00-04: 00 UT (04: 00-07: 00 LT) time bin (see Fig. 5), TEC-CTR does not vary much with F10.7 solar flux. The correlation coefficient for this relation is 0.35 . While for the 16: 00-20: 00 UT (19: 00-23: 00 LT) time bin (see Fig. 6), there seem to be a good correlation with F10.7 solar flux, with correlation coefficient of 0.76 . The good relation seen in Fig. 6 suggests that the evening pre-reversal which causes enhancement of the F2 region's plasma $\overrightarrow{\mathrm{E}} \times \overrightarrow{\mathrm{B}}$ drift near the equatorial anomaly region is dependent on solar activity (Zhang et al., 2009). As a result, TEC values at the crest regions are more enhanced in the evening hours than in the early morning hours.

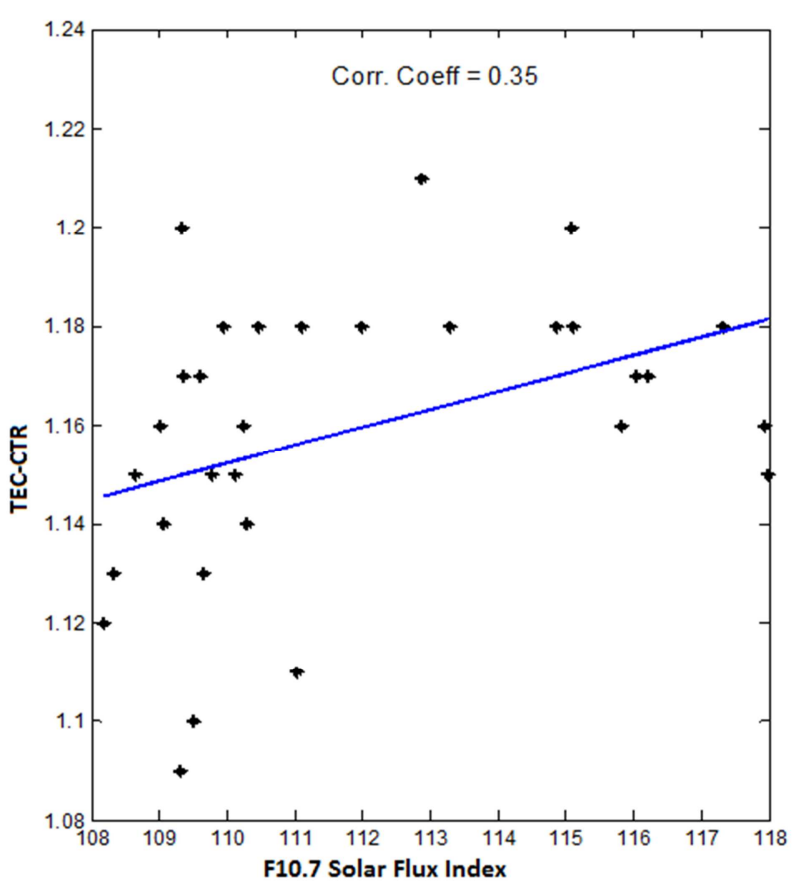

Fig. 5. Crest-to-Trough TEC Ratio versus F10.7 solar flux index for the 01: 00-04: 00 UT (04: 00-07: 00 LT) time bin. 
Since the TEC-CTR is a measure of the EIA strength, it is closely related to the equatorial vertical plasma drift, which is driven by the E X B field. The daytime average upward equatorial F-region vertical drift caused by electric field do not vary much with solar activity, but the evening upward drifts increase from solar minimum to solar maximum (Fejer and Scherliess, 2001). Fejer and Scherliess, 2001 therefore suggested that this behaviour of the dependence of the equatorial F-region vertical drifts on the solar activity causes a similar solar activity dependency of TEC-CTR in the equatorial anomaly region.

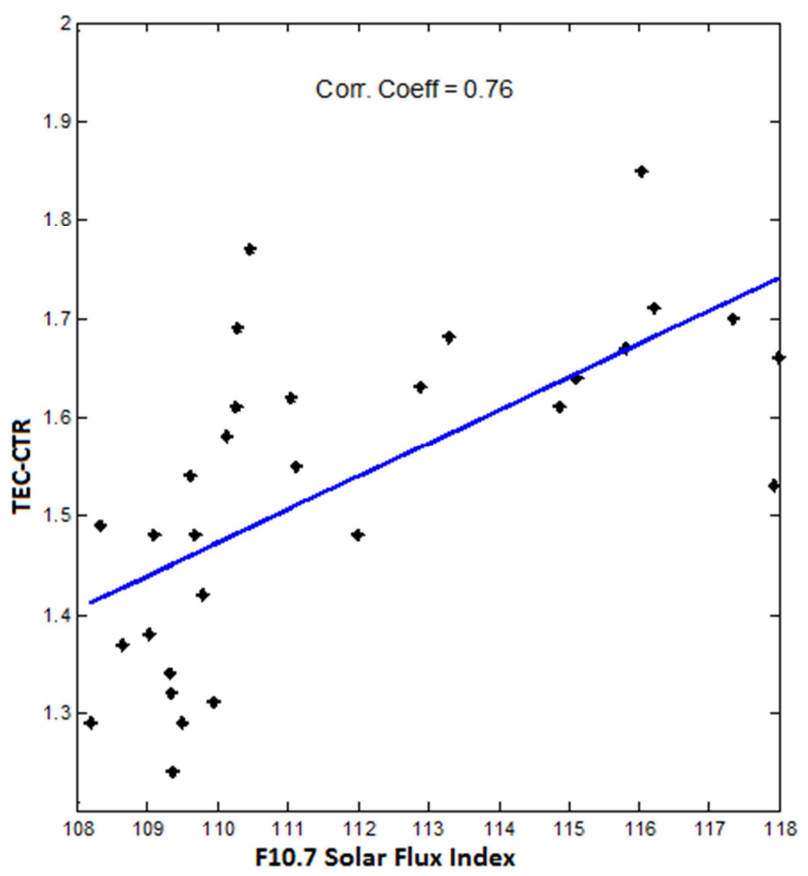

Fig. 6. Crest-to-Trough TEC Ratio versus F10.7 solar flux index for the 16 : 00-20: 00 UT (19: 00-23: 00 LT) time bin.

\subsection{Seasonal TEC-CTR Variations}

Seasonal TEC-CTR variations were studied by using TEC values for the Equinoxes (March, April and September, October), Summer Solstice (May, June, July and August) and Winter Solstice (November, December, January and February). For each season, only 20 days (of each month of the season) with full TEC data were considered for this study. This was done for convenience in order to discriminate against days with missing or incomplete data. Seasonal TEC values at crest station (MAL2) were then divided by their corresponding values at the trough station (ADIS). The resulting values were then separately presented on the same graph as shown in Fig. 7.

It can be clearly observed from Fig. 7 that TEC-CTR showed two peaks. One peak occurred in the post-midnight hours and the second (highest) peak in the post-sunset hours for all the seasons. This could be due to the enhancement of equatorial fountain strength. The post-sunset peak reaches maximum value in the equinoctial months while the presunrise peak reaches maximum value during the winter solstices. TEC-CTR had larger values in the winter solstice than in the summer solstice, a condition known as winter anomaly effect. Winter anomaly of TEC itself is largely a neutral composition effect resulting from the global thermospheric circulation and it confirms the existence of hemispheric difference (Pavlov and Pavlova, 2005a; Rishbeth et al., 2000). The findings of this study on TECCTR agree with that of Zhang et al., (2009) who studied the variability of TEC-CTR of EIA using GPS data obtained from Chinese network stations, South-East Asian stations and Australian stations for the years 1998-2004. Their study was conducted for both the southern and northern equatorial anomaly crest regions. They observed that TEC-CTR is a measure of the EIA strength, which is more closely related to the strength of the fountain effect. They also reported that on average, the post-sunset equatorial upward drift induced by electric field is higher in northern winter than in northern summer. This shows that winter anomaly effect in TEC-CTR exists simultaneously in both hemispheres as a result of the common driver electric fields.

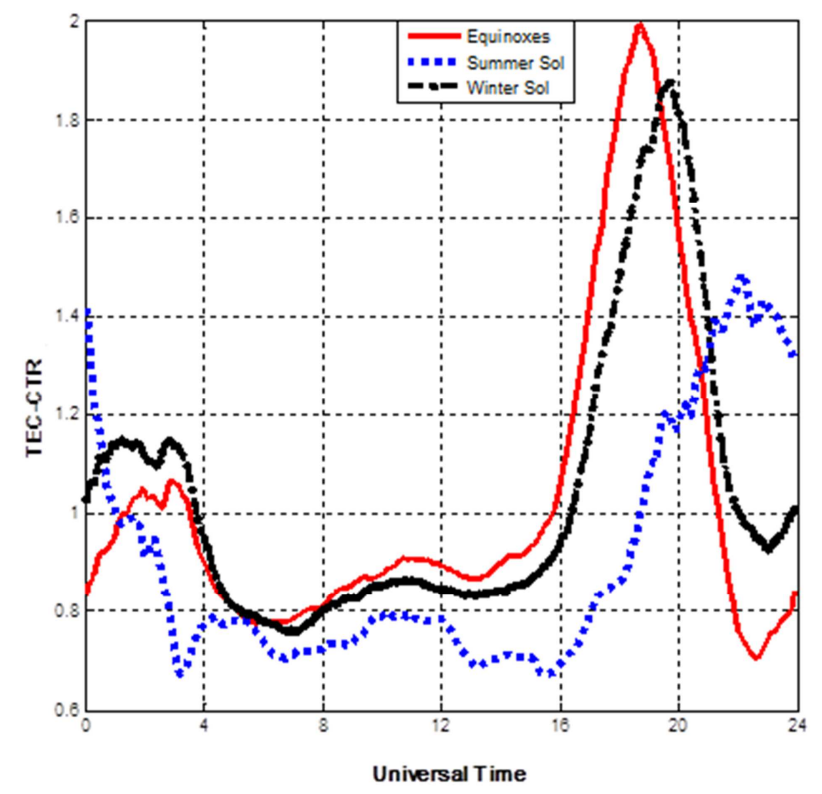

Fig. 7. Diurnal seasonal variation of the TEC-CTR of Equatorial Ionization Anomaly for the year 2012.

\section{Conclusions}

In this study, the vertical total electron content (TEC) deduced from the dual-frequency GPS measurements that are obtained at two ground stations around $110^{\circ} \mathrm{E}$ geomagnetic longitude during the high solar activity year, 2012. The main features of the TEC-CTR's diurnal and seasonal variations as well as their solar activity level dependency were investigated in this study. The results obtained showed that the diurnal variation pattern of TEC-CTR is characterized by two remarkable peak values, one occurring in the postmidnight hours around 02: 00-03: 00 UT (05: 00-06: 00 LT) and the second (highest) peak occurred in the post-sunset hours around 18: 00-20: 00 UT (21: 00-23: 00 LT). This 
means that EIA is regenerated (enhanced) to reach its largest strength in the post-sunset hours before midnight.

Seasonal TEC-CTR variations showed a semi-annual variation pattern, with maximum peak values occurring in the equinoctial months. TEC-CTR also revealed an existence of winter anomaly in this region, with higher values of TECCTR in the winter solstice than summer solstice. TEC-CTR in the daytime post-noon hours; between 01: 00-04: 00 UT (04: 00-07: 00 LT) does not vary much with the solar activity; however, TEC-CTR in the post-sunset hours; between 16: 00-20: 00 UT (19: 00-23: 00 LT) shows a clear dependence on the solar activity, with its values increasing with solar activity. This is due to the similar dependence of the equatorial F-region vertical drifts on the solar activity.

\section{References}

[1] Abdullah, M.; Bahari S. A. \& Yatim, B. (2008). TEC determination over single GPS receiver station using PPP technique, International Symposium on GPS/GNSS 2008, November 11-14, 2008 Tokyo.

[2] Adewale A. O.; Oyeyemi E. O.; Adeloye, A. B.; Ngwira C. M.; Athieno R. (2011). Responses of equatorial $F$ region to different geomagnetic storms observed by GPS in the African sector, J. Geophys. Res. VOL. 116, A12319, doi: 10.1029/2011JA016998

[3] Alex, S., Koparkar, P. V., Rastogi, R. G. (1989). Spread-F and ionization anomaly belt. J. Atmos. Terr. Phys. 51, 371-379.

[4] Balan, N., Otsuka, Y., Bailey, G. J., and Fukao, S.: Equinoctial asymmertries in the ionosphere and thermosphere observed by the MU radar, J. Geophys. Res., 103, 9481-9495, 1998.

[5] Breed, A. M. (1996). Investigation of the ionosphere over Australia using satellite transmissions, $\mathrm{PhD}$ thesis, School of Applied Physics, University of South Australia.

[6] Chakraborty, S. K and Hajra, R. (2009). Electrojet control of ambient ionization near the crest of the equatorial anomaly in the Indian zone. Ann. Geophys, 27, 93-105. www.anngeophys.net/27/93/2009/.

[7] Chakraborty, S. K., Hajra, R., 2007. Solar control of ambient ionization of the ionosphere near the crest of the equatorial anomaly in the Indian zone. Bull. Astron. Soc. India 35, 599605 .

[8] D'ujanga, F. M; Mubiru, J.; Twinamasiko, B. F.; Basalirwa, C and Ssenyonga, T. J. (2012). Total electron content variations in equatorial anomaly region. Advances in Space Research. 50(4), 441-449. DOI: 10.1016/j.asr.2012.05.005

[9] Essex, E. A.: Equinoctial variations in the total electron content of the ionosphere at northern and southern hemisphere stations, J. Atmos. Terr. Phys., 39, 645-650, 1977.

[10] Farley, D. T., Bonelli, E., Fejer, B. G., Larsen, M. F. (1986). The prereversal enhancement of the zonal electric field in the equatorial ionosphere. J. Geophys. Res. 91, 13723-13728.

[11] Fayose, R. S., Babatunde, R., Oladosu, O., Groves, K., (2012). Variation of total electron content and their effect on GNSS over Akure, Nigeria. Appl. Phys. Res. 4 (2). http: //dx.doi.org/10.5539/apr.v4n2p105.
[12] Feichter, E., Leitinger, R., 1997. A 22-year cycle in the F layer ionization of the ionosphere. Ann. Geophys. 15, 1015-1027. Bailey et al., 2000;

[13] Fejer, B. G., L. Scherliess, and E. R. de Paula (1999), Effects of the vertical plasma drift velocity on the generation and evolution of equatorial spread F, J. Geophys. Res., 104(A9), $19,859-19,869$.

[14] Fejer, B. G., de Paula, E. R., Heelis, R. A., Hanson, W. B. (1995). Global equatorial ionospheric vertical plasma drifts measured by the AE-E satellite. J. Geophys. Res. 100 (4), $5769-5776$.

[15] Fejer, B. G.; Scherliess, L. (2001). On the variability of equatorial F-region vertical plasma drifts. J. Atmos. Terr. Phys. 63 (9), 893-897.

[16] Goodman, J. M. (2005). Space Weather and Telecommunications. Radio Propagation Services, Inc., USA. (RPSI). Alexandria VA 22308-1943. ISBN 0-387-23670-8

[17] Hansen, A.; Blanch, J. \& Walter, T. et al. (2000). Ionospheric correction analysis for WAAS quiet and stormy. ION GPS, Salt Lake City, Utah, September 19-22, 2000, pp 634-642, America.

[18] Henderson, S. B., Swenson, C. M., Christensen, A. B., Paxton, L. J. (2005). Morphology of the equatorial anomaly and equatorial plasma bubbles using image subspace analysis of Global Ultraviolet Imager data. J. Geophys. Res. 110, A11306, doi: 10.1029/2005JA011080.

[19] Horvath, I \& Essex, E. A. (2000). Using observations from the GPS and TOPEX satellites to investigate night-time TEC enhancement at mid-latitudes in the southern hemisphere during a low sunspot number period, Journal of Atmospheric and solar Terissterial-Physics, Vol. 62, No. 5, pp. 371-391.

[20] Jakowski, N., Sardon, E., Engler, E., Jungstand, A., and Klhn, D. (1996). Relationships between GPS-signal propagation errors and EISCAT observations, Ann. Geophys., 14, 1429 1436, http: //www.ann-geophys.net/14/1429/1996/.

[21] Jayachandran, P. T., Sri R. P., Somayajulu, Y. V., Rama Rao, P. V. S. (1997). Effect of equatorial ionization anomaly on the occurrence of spread-F. Ann. Geophys. 15, 255-262.

[22] Kelley, M. C. (1989), The Earth's Ionosphere, Academic Press, London.

[23] Kherani, A., De-Paula, E., Olusegun, J., 2013. Observations and simulations of equinoctial asymmetry during low and high solar activities. In: Presentation at a Proceeding of the Thirteenth International Congress of the Brazilian Geophysical Society, held in Rio de Janeiro, Brazil, August 26-29.

[24] Klobuchar, J. A. (1991). Ionospheric effects on GPS, GPS World, 48-51.

[25] Klobuchar, J. A. (1996) Ionospheric effects on GPS, in: Global Positioning System: Theory and application Vol. 1, edited by: Parkinson, B. W. and Spilker, J. J., American Institute of Aeronautics and Astronautics INC.

[26] Lanyi, G. E. and Rolh, T. (1988). A comparison of mapped and measured total ionospheric electron content using global positioning system and beacon satellite observations, Radio Sci., 23, 483-492. 
[27] Liu, L., He, M., Yue, X., Ning, B., Wan, W., (2010). Ionosphere around equinoxes during low solar activity. J. Geophys. Res. 115, A09307. http: //dx.doi.org/10.1029/ 2010JA015318.

[28] Memarzadeh, Y. (2009). Ionospheric Modeling for Precise GNSS Applications. Master's Thesis. ISBN-13 978-90-6132314-3

[29] Mukherjee, S.; Sarkar, S.; Purohit, P. K.; Gwal, A. K. (2010). Seasonal variation of total electron content at crest of equatorial anomaly station during low solar activity conditions. Adv. Space Res. 46 (3), 291-295.

[30] Ngwira C. M., Klenzing J., Olwendo J., D’ujanga F. M., Stoneback R. and Baki P., (2013b). A study of intense ionospheric scintillation observed during a quiet day in the East African low latitude region. Radio Science, 48, 1-9, doi: 10.1002/rds.20045.

[31] Ngwira, C. M., G. K. Seemala, and J. B. Habarulema (2013a), Simultaneous observations of ionospheric irregularities in the African low-latitude region, J. Atmos. Sol.-Terr. Phys., 97, 50 57, doi: 10.1016/j.jastp.2013.02.014.

[32] Okonkwo, P and Ugwuanyi, J. (2012). IRI and GPS TEC Variations over Ilorin, Nigeria. Journal of Space Science \& Technology. 1(3), 1-11.

[33] Olwendo, O. J., Baki, P., Cilliers, P. J., Mito, C., Doherty, P., (2012). Comparison of GPS TEC measurements with IRI-2007 TEC prediction over the Kenyan region during the descending phase of solar cycle 23. Adv. Space Res. 49, 914-921.

[34] Oron, S.; D'ujanga, F. M and Ssenyonga, T. J. (2013). Ionospheric TEC variations during the ascending solar activity phase at an equatorial station, Uganda. Indian Journal of Radio and Space Physics. 42, 7-17.

[35] Oryema, B., Jurua, E., D'ujanga, F. M., and Ssebiyonga, N. (2015). Investigation of TEC variations over the magnetic equatorial and equatorial anomaly regions of the African sector. Adv. Space Res. (2015), http: //dx.doi.org/10.1016/j.asr.2015.05.037

[36] Ouattara, F and Fleury, R. (2011). Variability of CODG TEC and IRI 2001 total electron content (TEC) during IHY campaign period (21 March to 16 April 2008) at Niamey under different geomagnetic activity conditions. Scientific Research and Essays, 6 (17), 3609-3622.

[37] Pavlov, A. V.; Pavlova, N. M. (2005a). Causes of the midlatitude $\mathrm{NmF} 2$ winter anomaly at solar maximum. J. Atmos. Terr. Phys. 67, 862-877.

[38] Paznukhov, V. V., et al. (2012), Equatorial plasma bubbles and L-band scintillations in Africa during solar minimum, Ann. Geophys., 30, 675-682.

[39] Richards, P. G.: Seasonal and solar cycle variations of the ionospheric peak electron density: comparison of measurement and models, J. Geophys. Res., 106 (A12), 12 803-12 819, 2001.

[40] Rishbeth, H.; Muller-Wodarg, I. C. F.; Zou, L.; Fuller-Rowell, T. J.; Millward, G. H.; Moffett, R. J.; Idenden, D. W.; Aylward, A. D. (2000). Annual and semiannual variations in the ionospheric F2-layer: II. Physical discussion. Ann. Geophys. 18, 945-956.
[41] Sardon, E., Rius, A., and Zarraoa, N. (1994). Estimation of the receiver differential biases and the ionospheric total electron content from Global Positioning System observations, Radio Sci., 29, 577-586.

[42] Schaer, S.; Markus, R.; Gerhard, B. \& Timon, A. S. (1996). Daily Global Ionosphere Maps based on GPS Carrier Phase Data Routinely produced by the CODE Analysis Center, Proceeding of the IGS Analysis Center Workshop, Silver Spring, Maryland, pp. 181-192, USA.

[43] Schunk, R. W and Nagy, A. F. (2000). Ionospheres. Cambridge University Press, New York.

[44] Seemala, G. K., and C. E. Valladares (2011), Statistics of total electron content depletions observed over the South American continent for the year 2008, Radio Sci., 46, RS5019, doi: $10.1029 / 2011$ RS004722.

[45] Titheridge, J. E. (1972). The total electron content of the southern mid-latitude ionosphere, 1965-1971, J. Atmos. Terr. Phys., 35, 981-1001.

[46] Titheridge, J. E.: The electron content of the southern midlatitude ionosphere, 1965-1971, J. Atmos. Terr. Phys., 981$1001,1973$.

[47] Titheridge, J. E., Buonsanto, M. J., 1983. Annual variations in the electron content and height of the F layer in the Northern and Southern Hemispheres, related to neutral composition. J. Atmos. Terr. Phys. 45, 683-696.

[48] Tsai, H. F., Liu, J. Y., Tsai, W. H., Liu, C. H., Tseng, C. L., $\mathrm{Wu}, \mathrm{C}$-C. Seasonal variations of the ionospheric total electron content in Asian equatorial anomaly regions. J. Geophys. Res. 106 (A12), 30363-30370, 2001.

[49] Tsai, H. F; Liu, J. Y; Tsai, W. H and Liu, C. H. (2001). Seasonal variations of the ionospheric total electron content in Asian equatorial anomaly regions. Journal of Geophysical research. 106 (A12), 30, 363-30, 369.

[50] Valladares, C. E., Basu, S., Groves, K., Hagan, M. P., Hysell, D., Mazzella Jr., A. J., Sheehan, R. E. (2001). Measurements of the latitudinal distributions of total electron content during equatorial spread F events. J. Geophys. Res. 106 (A12), 29133-29152.

[51] Valladares, C. E., Villalobos, J., Sheehan, R., Hagan, M. P. (2004). Latitudinal extension of low-latitude scintillations measured with a network of GPS receivers. Ann. Geophys. 22, $3155-3175$.

[52] Whalen, J. A. (2004). Linear dependence of the post-sunset equatorial anomaly electron density on solar flux and its relation to the maximum pre-reversal ExB drift velocity through its dependence on solar flux. J. Geophys. Res. 109, A07309, doi: 10.1029/2004JA010528.

[53] Wu, C. C., Liou, K., Shan, S.-J., Tseng, C.-L. Variation of ionospheric total electron content in Taiwan region of the equatorial anomaly from 1994 to 2003. Adv. Space Res. 41 (2008), 611-616, doi: 10.1016/j.asr.2007.06.013, 2008.

[54] Yeh, K. C., Franke, S. J., Andreeva1, E. S., Kunitsyn, V. E. An investigation of motions of the equatorial anomaly crest. Geophys. Res. Lett. 28 (24), 4517-4520, 2001.

[55] Yue, X; Schreiner, W. S; Kuo, Y. H; Lei, J. (2015). Ionosphere equatorial ionization anomaly observed by GPS radio occultations during 2006-2014, JASTP, 30-40. 
[56] Zhang, M. L.; Wan, W.; Liu, L.; Ning, B. (2009). Variability study of the crest-to-trough TEC ratio of the equatorial ionization anomaly around $120^{\circ} \mathrm{E}$ longitude. Advances in Space Research. 43, 1762-1769.

[57] Zhao, B; Wan, W; Liu, L and Ren, Z. (2009). Characteristics of the ionospheric total electron content of the equatorial ionization anomaly in the Asian-Australian region during 1996-2004. Ann. Geophys., 27, 3861-3873. www.anngeophys.net/27/3861/2009/
[58] Zhao, B; Wan, W; Liu, L; Mao, T; Ren, Z; Wang, M and Christensen, A. B. (2007). Features of annual and semiannual variations derived from the global ionospheric maps of total electron content, Ann. Geophys., 25, 2513-2527.

[59] Zoundi, C.; Ouattara, F.; Fleury, R.; Amory-Mazaudier, C and Duchesne, L. P. (2012). Seasonal TEC Variability in West Africa Equatorial Anomaly Region. European Journal of Scientific Research. ISSN 1450-216X. 77 (3), 303-313. 